\title{
Renal Cell Injury: Metabolic and Structural Alterations
}

\author{
NORMAN J. SIEGEL, PRASAD DEVARAJAN, AND SCOTT VAN WHY \\ Department of Pediatrics, Division of Nephrology, Yale University School of Medicine, \\ New Haven, Connecticut 06520-8064
}

Over the past several decades, the pathophysiologic mechanisms by which renal tubule cells are injured have been the subject of intensive investigation. Although it is clear that a number of factors contribute to the susceptibility and the degree of injury, the interrelationship between metabolic alterations and structural changes has provided some important new insights. A clear example of the way in which differences in cellular metabolism can effect injury is demonstrated by contrasting the straight $\left(\mathrm{S}_{3}\right)$ segment of the proximal tubule and the medullary thick ascending limb (mTAL). Because of a dependence on oxidative phosphorylation for energy in the adult animal, the $S_{3}$ segment is particularly susceptible to renal ischemia and those nephrotoxins that disrupt mitochondrial function and energy supply $(1,2)$. Even brief periods of ischemia result in structural changes such as sloughing of the brush border, whereas prolonged ischemia produces irreversible changes in some cells and sublethal alterations such as swelling and mitochondrial condensation in others $(2,3)$. These changes take place rapidly and, with mild injury, repair and restitution of cellular structure is quickly accomplished. In contrast, the mTAL is much more susceptible to hypoxia, an observation that was first made in isolated perfused kidneys when a cellfree perfusate was being used (4). The unique susceptibility of this segment to hypoxia can be prevented when red blood cells or $\mathrm{Hb}$ is added to the perfusate, indicating the crucial importance of a threshold for oxygen delivery in the renal medulla (5). The mitochondrial swelling and nuclear pyknosis that is characteristic of the mTAL lesion can be modified by inhibiting transport in this segment with agents such as furosemide or ouabain (4). In contrast, maneuvers that increase the workload in the mTAL segment have been shown to cause more severe structural damage with complete cellular disruption (4). The differential response of these two nephron segments is a clear demonstration of the intricate relationship between metabolic factors and the cellular targets for renal epithelial injury. This review will focus on ischemic acute

Correspondence: Norman J. Siegel, M.D., Yale University School of Medicine. Department of Pediatrics, 333 Cedar St.. P.O. Box 208064, New Haven, ('T (o6520-8064.

Supported by NIH DK-44336; NIH DK-47072. NIH HD-27757, Baxter Extra mural Grant Program, Donaghue Foundation. American Heart Asseciation. Clinician Scientist Award, and the Charles H. Hood Foundation. renal failure, which has been extensively studied and represents a model system in which alterations in cellular metabolism and consequent changes in renal cell structure can be readily appreciated. Three interrelated aspects of ischemic injury to renal epithelial cells will be discussed: adenine nucleotide metabolism, cellular structure and integrity, and response of heat shock proteins.

\section{ADENINE NUCLEOTIDE METABOLISM}

In 1968, Voight and Farber (6) documented that, within 5-10 min of complete occlusion of the renal artery, cellular ATP levels fell by $85-90 \%$. With the application of in vivo nuclear magnetic resonance spectroscopy, it has been possible to further delineate alterations in adenine nucleotide metabolism that occur as a consequence of renal hypoperfusion or ischemia $(7,8)$. Three phases of this relationship have been found to be of particular importance (Fig. 1). During the first phase, which follows reduction of blood flow to the kidney, there is a relatively rapid decrease in cellular ATP levels. Little or no change in renal cell ATP is noted when the degree of arterial occlusion is less than $50 \%$. However, there is a concomitant reduction in cellular ATP to new steady state levels as renal perfusion is progressively reduced. When renal perfusion is completely eliminated, cellular ATP levels are reduced rapidly to values that are $20-25 \%$ of preischemic levels. Oxygen consumption can be used to assess the components of cellular energy that are depleted when cellular ATP is reduced (Fig. 2). Under basal conditions, oxygen is consumed for both transport-related and nontransport functions. Oxygen consumption measured after addition of ouabain is related to nontransport activity. In both an ischemic injury (9) and a toxic insult (10), a preferential decrease in energy related to active transport occurs, whereas energy devoted to nontransport functions is minimally affected. When renal cells are faced with a diminished supply of ATP, transport-related functions are given up and energy is conserved for basic functions that may be essential for survival of sublethally injured cells.

The second phase of adenine nucleotide metabolism occurs immediately upon reperfusion, during which there is a rapid recovery of cellular ATP to levels that are $50-70 \%$ of preischemic values (Fig. 1). The degree of 


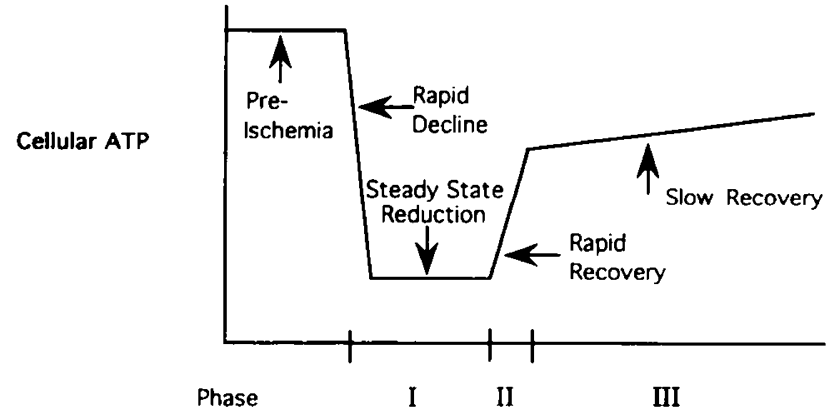

Figure 1. Schematic representation of the alterations in cellular ATP that occur during and after renal ischemia as determined by in vivo nuclear magnetic resonance spectroscopy. During phase I, ATP is rapidly depleted to a steady state level that depends on the degree of reduction in renal blood flow. Immediately upon reflow, phase II, cellular ATP returns toward preischemic values and the level of recovery is related to the residual adenine nucleotide pool during ischemia (phase I). During phase III, cellular ATP continues to recover but at a slower rate, which is dependent on complex mechanisms of ATP synthesis.

ATP recovery during this rapid phase correlates well with the total pool of adenine nucleotides (ATP + ADP + AMP) that is present at the end of the ischemic interval (Fig. 3). Thus, with partial renal artery occlusion or with short periods of complete renal artery occlusion, the degree of ATP recovery is greater during early reflow, whereas prolonged complete occlusion results in diminished ATP recovery during phase II (7).

The third phase of adenine nucleotide metabolism is relatively slow and results in the reaccumulation of cellular ATP during the first $2 \mathrm{~h}$ of reperfusion (Fig. 1). The critical factors for ATP resynthesis during phase III are the availability of adenine nucleosides (adenosine and inosine), the salvage pathways (Fig. 3), and de novo purine synthesis (11). For example, with prolonged ischemia, ATP is progressively degraded to AMP and adenosine, which may be metabolized irreversibly to inosine. These breakdown products of ATP catabolism, the adenine nucleosides and bases, are more membrane permeable and thus more likely to be lost from the kidney during reperfusion. Thus, the third phase of ATP regen-

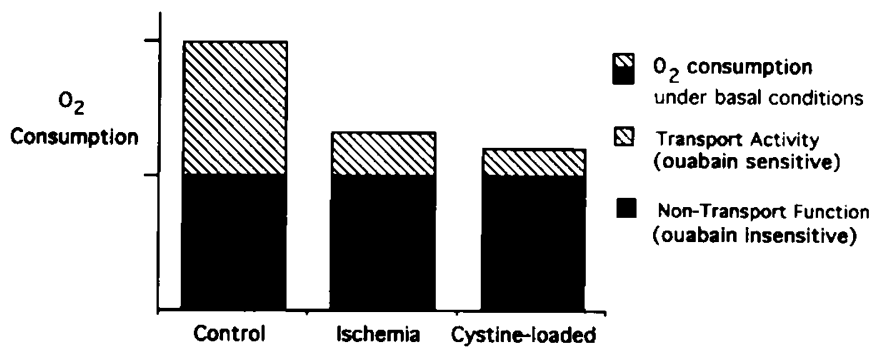

Figure 2. Schema showing cellular energy distribution determined by oxygen consumption in suspensions of renal tubules. The sum of transport and nontransport oxygen consumption (height of each bar) is determined under basal (nonstimulated/noninhibited) conditions. When ATP is depleted by ischemia (9) or cystine loading (10), the component of cellular ATP devoted to essential processes (black portion) is preferentially preserved compared with transport-related energy (striped portion).

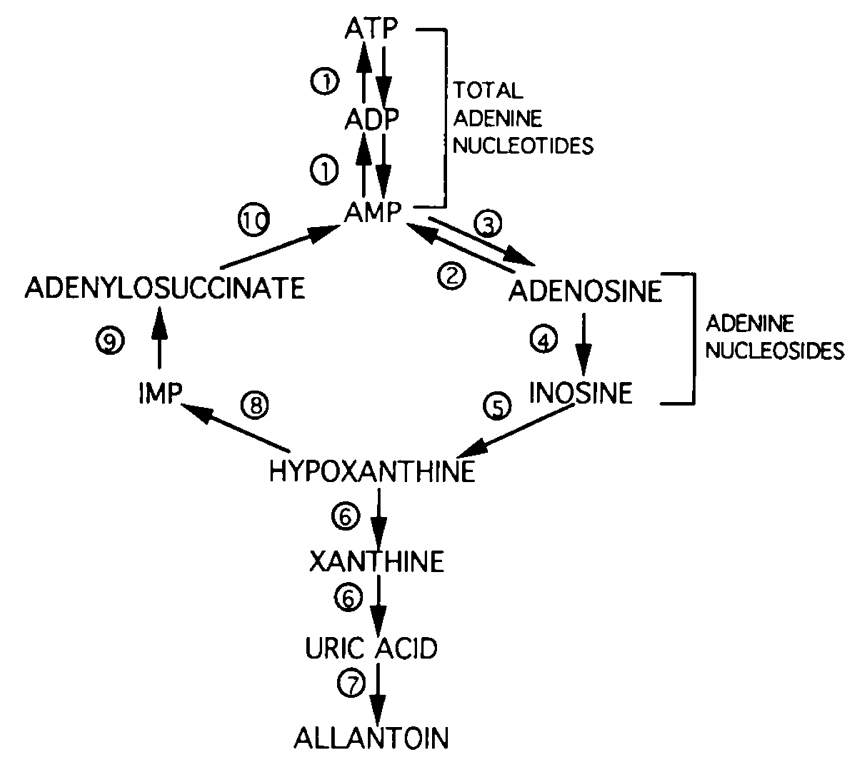

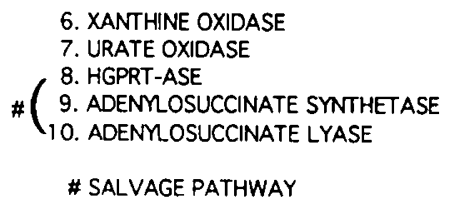

\# SALVAGE PATHWAY

Figure 3. Schematic representation of adenine nucleotide metabolic pathways. With ischemia or oxygen deprivation, adenine nucleotides are degraded, clockwise, and recovery of cellular ATP during reflow is dependent on the residual total adenine nucleotide pool at the end of the ischemic event and availability of adenine nucleosides and salvage pathways during reflow. IMP, inosine monophosphate; HGPRT, hypoxanthine guanine phosphoribosyltransferase.

eration is particularly important with respect to the severity of the injury, and the restoration of cellular ATP is critically dependent on the ability of injured cells to effectively use endogenous precursors during reperfusion.

These important alterations in adenine nucleotide metabolism have been correlated with the degree of renal functional impairment and structural alterations $(7,8,12$, 13). For example, animals subjected to progressive degrees of renal hypoperfusion develop acute renal failure only when severe ATP depletion occurs (13), and when renal perfusion is altered to the same degree only those animals in which ATP is severely depleted develop evidence of functional impairment (12). Based on these observations, the concept that cellular ATP levels are both a consequence of the ischemic insult and, possibly, a predictor of renal cell injury has been carefully evaluated.

A pivotal role of energy depletion and restoration in an ischemic renal injury is supported by studies in which 1 ) ATP catabolism has been inhibited during ischemia (14, 15) and 2) ATP recovery has been augmented during phase III (16-20). ATP catabolism (Fig. 3) has been inhibited with two compounds: 2-deoxycoformycin, which blocks the conversion of adenosine to inosine, and adenosine- $\alpha, \beta$ methylene diphosphonate, which inhibits the conversion of AMP to adenosine $(14,15)$. In both 
cases, the total pool of adenine nucleotides at the end of the ischemic injury was increased, resulting in a greater recovery of ATP during the rapid phase of resynthesis as well as an increase in the third phase of ATP recovery. The degree of impairment of renal function was significantly less in both groups of animals compared with nontreated controls. When the conversion of adenine nucleotides to adenine nucleosides had been completely inhibited by the administration of adenosine- $\alpha, \beta$ methylene diphosphate, the animals that had been subjected to $45 \mathrm{~min}$ of ischemia had a pattern of recovery of cellular ATP and renal function that was quite similar to that of animals subjected to only $15 \mathrm{~min}$ of ischemia. Thus, by manipulating adenine nucleotide metabolism, the degree of renal injury could be altered.

The recovery of cellular ATP during the first $2 \mathrm{~h}$ of reflow can be augmented by the postischemic infusion of adenine nucleotides combined with magnesium chloride or thyroxin (16-20). The early rapid phase of ATP recovery is not affected because these compounds are given during the first $30 \mathrm{~min}$ of reflow, but the slower phase (phase III) is significantly enhanced. Thus, the cellular ATP levels at 120 min of reflow are substantially higher in animals given a postischemic infusion of either adenine nucleotides combined with magnesium chloride or thyroxin. This accelerated recovery of cellular ATP is associated with improved glomerular and tubular function, augmented recovery of cellular structure, and a sustained recovery of renal function (16-20). The primary mechanism by which the postischemic infusion of adenine nucleotides combined with magnesium chloride is effective has been demonstrated to be provision of precursors (principally adenosine) for the resynthesis of ATP and a stimulation of de novo purine synthesis (11). Postischemic thyroxin stabilizes the mitochondrial adenine nucleotide transporter, which is critical for the production of ATP and has been shown to stimulate cellular proliferation $(21,22)$.

These alterations in cellular energy metabolism are closely linked to a large number of factors that contribute to renal cell injury (23). A depletion of cellular ATP can be expected to result in alterations in intracellular calcium, the production of reactive oxygen molecules, and the activation of phospholipases and proteases with degradation of the plasma membrane. Recent reviews of renal cell injury have addressed the relative role and contribution of each of these factors $(23,24)$.

\section{CELLULAR STRUCTURE AND INTEGRITY}

The alterations in cellular polarity and cytoskeletal assembly that occur as a consequence of renal ischemia are critical factors in the loss of epithelial structure and integrity. Polarized epithelial cells play fundamental roles in the ontogeny and functions of a variety of organs and tissues (25-27). Polarity is especially critical to renal epithelial cells, which perform the crucial functions of cell volume regulation and vectorial transport of ions and nutrients. This is made possible largely by the asymmetric targeting of the driving force, $\mathrm{Na}, \mathrm{K}$-ATPase, to the basolateral membrane (27-29). An initial requirement for the generation of cellular polarity seems to be the establishment of cell-cell contacts and tight junctions, which delineate the biochemically distinct apical and basolateral membrane compartments $(30,31)$. In renal tubule cells, the apical membrane is on the luminal aspect, whereas the basolateral domain faces the vascular side. The mechanisms by which specific enzymes, transporters, receptors, and lipids reach their membrane destinations are complex and incompletely understood. For example, it has been proposed by some investigators that $\mathrm{Na}, \mathrm{K}-\mathrm{ATP}$ ase subunits are targeted directly to the basolateral domain $(32,33)$, whereas others have suggested that Na,K-ATPase goes initially to both domains followed by preferential retention of the enzyme in the lateral surface and selective loss from the apical domain (34). In either case, polarized membrane proteins must be restricted to the targeted domain and protected from lateral diffusion or endocytosis. Although the tight junctions may restrict diffusion of some integral membrane proteins within the lipid bilayer, a polarized distribution of $\mathrm{Na}, \mathrm{K}$-ATPase can be generated and maintained even in the absence of tight junctions (35). However, several recent findings suggest that the actin-based cytoskeleton plays a key role in the stabilizations of the polarized state $(25-29,36,37)$.

Renal ischemia, in vivo, or intracellular ATP depletion, in vitro, induces the rapid relocation of apical and basolateral membrane-specific proteins and lipids into the alternate membrane domain (27-43). Because of the central role of $\mathrm{Na}, \mathrm{K}-\mathrm{ATPase}$ in renal tubule cell function, this protein has been examined in detail and used as a model for alterations in cell polarity after ischemia. After as little as 5 min of ATP depletion, there is loss, internalization, and blebbing of apical brush-border membranes and, shortly thereafter, the basolateral Na,K-ATPase migrates to the apical domain $(28,44)$. This results in significant cellular dysfunction, as exemplified by the marked reduction in proximal tubular reabsorption of sodium, water, and glucose (45-47). Reestablishment of basolateral $\mathrm{Na}, \mathrm{K}$ ATPase localization occurs during recovery and is a necessary prerequisite for restoration of tubular function (46). Several biochemical, histochemical, and immunocytochemical studies have recently detailed the changes in $\mathrm{Na}, \mathrm{K}$-ATPase polarity after renal ischemia.

Initial biochemical evidence for the loss of $\mathrm{Na}, \mathrm{K}$ ATPase polarity was obtained by Molitoris et al. $(44,48)$, who showed that brush-border membranes isolated from ischemic rat kidneys displayed increased $\mathrm{Na}, \mathrm{K}$-ATPase enzyme activity in apical membranes compared with basolateral membranes. This redistribution of $\mathrm{Na}, \mathrm{K}$ ATPase into the apical domain has been confirmed in situ in proximal tubule cells after ischemia $(44,49)$.

For Na,K-ATPase to be translocated to the apical domain, it must first be detached from its cytoskeletal tether. A useful functional measure of the membrane 
attachment of any given protein is the extractability of that protein in the detergent Triton X-100. When a protein is found in the detergent-soluble fraction, it is defined as being disassembled. When intracellular ATP depletion is induced in confluent monolayers of proximal tubule cells and the distribution of $\mathrm{Na}, \mathrm{K}$-ATPase is analyzed by Triton X-100 extraction (29), there is a marked increase in the Triton-extractable Na,K-ATPase, suggesting that it has been released from the cytoskeleton. Renal ischemia in vivo also results in increased Triton-extractable $\mathrm{Na}, \mathrm{K}$ ATPase in rat renal proximal tubule cells (37). However, although these studies have demonstrated that severe intracellular ATP depletion is associated with a loss of $\mathrm{Na}, \mathrm{K}-\mathrm{ATPase}$ polarity, determination of a threshold level of ischemia below which loss of polarity results and correlation of the degrees of injury with degrees of impaired polarity have not been accomplished.

Reestablishment of Na,K-ATPase polarity occurs during recovery from renal ischemia at a rate dependent on the severity of the insult and is preceded by restoration of cellular ATP. Several investigators have shown that total cellular $\mathrm{Na}, \mathrm{K}$-ATPase activity in homogenized renal cortical tissue is unaltered by ischemia. Moreover, after ischemia, there is no increase in immunodetectable levels of $\mathrm{Na}, \mathrm{K}$-ATPase subunits, and the rate of transcription of each subunit is decreased in parallel with the overall transcription rate (50). These findings suggest that recycling of misplaced Na,K-ATPase subunits, rather than increased biosynthesis, is the mechanism by which renal tubular cells repolarize after an ischemic insult.

These observations concerning cellular polarity suggest that concomitant alterations in the cytoskeleton of the renal epithelium would be likely to occur with ischemia in vivo or ATP depletion in vitro. The cytoskeleton is a ubiquitous network of interacting proteins coordinated into an integrated structure (Fig. 4), the basic role of which is the provision of order for integral membrane proteins (36). The major component of this network is fodrin, which links with actin to form a two-dimensional scaffolding. Ankyrins are a family of proteins that serve as adapters between the fodrin skeleton and integral

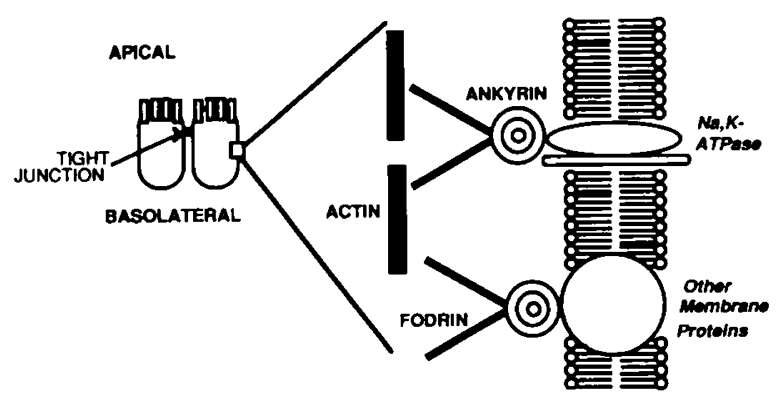

Figure 4. Schematic representation of polarized renal epithelium and the cytoskeletal structure of the lateral membrane domain. The formation of tight junctions delineates apical and basolateral domains. The lateral domain has a network of proteins that provide a linkage between integral membrane proteins, such as $\mathrm{Na}, \mathrm{K}$-ATPase, and the actin-based cytoskeleton. Fodrin links with actin, and ankyrin serves as an adapter between membrane proteins and fodrin. membrane proteins. Fodrin, ankyrin, and $\mathrm{Na}, \mathrm{K}$-ATPase are colocalized in the basolateral domains of renal tubule epithelial cells in situ, as well as in confluent distal tubule cells (38-42) in culture. Also, the Triton X-100 extractability of a fodrin-ankyrin-Na,K-ATPase complex is markedly reduced by cell-cell contact (43), indicating synchronized assembly of these proteins. Furthermore, a direct binding of ankyrin with the $\alpha$-subunit of $\mathrm{Na}, \mathrm{K}$ ATPase has been demonstrated in vitro $(39,42)$. Thus, ankyrins anchor $\mathrm{Na}, \mathrm{K}$-ATPase to the polarized fodrin cytoskeleton, thereby maintaining a basolateral distribution and reducing endocytic removal of $\mathrm{Na}, \mathrm{K}$-ATPase $(34,43)$. The actin-based cytoskeleton plays an important role in preserving the structural and functional integrity of apical microvilli and the tight junctions that exist between renal tubule cells $(28,29)$.

It is intriguing that the response of intact fodrin to renal ischemia does not parallel that of $\mathrm{Na}, \mathrm{K}$-ATPase, given the close interactions that exist between these proteins in nonischemic epithelial cells (49-53). Immunocytochemical studies on rat proximal tubules have demonstrated that after in vivo ischemia there was a loss of basolateral fodrin polarity but also a dissociation from $\mathrm{Na}, \mathrm{K}$ ATPase, with fodrin being detected diffusely throughout the cytoplasm (49). During recovery, fodrin was incompletely restored to a normal distribution, being partially codistributed with $\mathrm{Na}, \mathrm{K}$-ATPase along the basolateral membrane but also present in a diffuse cytosolic pattern in the subapical region. The significance of these differences in the behavior of fodrin and $\mathrm{Na}, \mathrm{K}$-ATPase is unclear.

Proteolytic processing of fodrin into cleavage products has been implicated in ischemic injury to the hippocampus (51). Because such degradation of fodrin may provide a mechanism for release of $\mathrm{Na}, \mathrm{K}-\mathrm{ATPase}$ from the cytoskeleton, the biosynthesis and processing of fodrin after renal ischemia has been investigated. Renal tissue rendered completely ischemic for $2 \mathrm{~h}$ displays only minimal breakdown of fodrin (52). However, fodrin seems to undergo proteolysis primarily during reperfusion after mild renal ischemia (44). Such processing is associated with the transient loss of $\mathrm{Na}, \mathrm{K}$-ATPase polarity that occurs specifically during early reperfusion. Furthermore, the appearance of fodrin cleavage products is markedly decreased once repolarization of $\mathrm{Na}, \mathrm{K}$ ATPase has occurred. This temporal pattern suggests a role for fodrin processing in the loss and return of $\mathrm{Na}, \mathrm{K}$ ATPase polarity during recovery from renal ischemia.

The response of ankyrin to renal ischemia is similar to that of Na,K-ATPase, at least at the morphologic level. After ischemia, there is a loss of polar distribution of ankyrin, with ankyrin immunodected in the apical domain and subapical vacuoles. After complete recovery, ankyrin codistributes with $\mathrm{Na}, \mathrm{K}$-ATPase in the basolateral membranes (49). However, the precise role of ankyrin in the loss and restitution of Na,K-ATPase polarity is far from clear. It is not known whether the $\mathrm{Na}, \mathrm{K}-\mathrm{ATPase}$ molecules that are disassembled after 
ischemia are also dissociated from ankyrin or whether they continue to be ankyrin bound. The former scenario would implicate defective ankyrin-Na,K-ATPase binding in the ischemia-induced loss of polarity. Conversely, if the disassembled Na,K-ATPase is still ankyrin bound, this would implicate defective assembly of ankyrin with some other protein, possibly fodrin.

Examination of ankyrin turnover after renal ischemia has yielded surprising results. Kidney tissue rendered completely ischemic displayed a major, time-dependent loss of ankyrin that was essentially complete at the end of $2 \mathrm{~h}$ of ischemia (52). This profound loss was not accompanied by an appearance of proteolytic degradation products and was not observed in ischemic brain or heart. These observations suggest that ischemia causes a significant tissue-specific inhibition of ankyrin mRNA transcription, stability, or translation. Early studies of the biosynthetic response of ankyrin during recovery from renal ischemia have revealed that by $2 \mathrm{~h}$ of reperfusion there is a significant loss of immunodectable intact ankyrin (unpublished observations) and a concomitant loss of $\mathrm{Na}, \mathrm{K}$-ATPase polarization by immunofluorescence (50). However, by $6 \mathrm{~h}$ of reflow, ankyrin abundance increases to levels close to those in control kidneys, at a time when restitution of $\mathrm{Na}, \mathrm{K}$-ATPase polarity has commenced. By $24 \mathrm{~h}$ of reperfusion, immunodetectable ankyrin levels exceed control levels, concomitant with restitution of $\mathrm{Na}, \mathrm{K}$-ATPase polarity. Based on this temporal sequence, it is intriguing to speculate that an increase in ankyrin biosynthesis may play a role in the return of Na,K-ATPase polarity during the recovery period. The molecular mechanisms responsible for increased ankyrin turnover remain to be elucidated.

In intact proximal tubules, actin is primarily associated with the circumferential terminal web at the apical pole. In vivo renal ischemia results in a redistribution of actin throughout the cytoplasm (54). After intracellular ATP depletion in cultured renal cells, there is a disruption of the actin cytoskeleton, conversion of monomeric $(\mathrm{G})$ to polymeric filamentous $(\mathrm{F})$ actin, and redistribution of F-actin from the membrane surface to a perinuclear and cytosolic localization (55). These changes coincide with a rapid decrease in the amount of cytoskeleton-associated $\mathrm{Na}, \mathrm{K}-\mathrm{ATPase}$, suggesting a role for actin microfilaments in the ischemia-induced loss of polarity. The behavior of actin during the recovery phase will be important to examine, because these microfilaments may play a crucial role in redirecting misplaced cytoskeletal elements to their proper destinations.

In vivo microperfusion studies of proximal tubules have revealed that ischemia results in a time-dependent penetration of tight junctions, secondary to disruption of the actin cytoskeleton (56). Disruption of tight junctions in vitro by other mechanisms has been shown to result in altered polarity of several membrane proteins and lipids (57). It is possible that postischemic opening of tight junctions allows the lateral intramembranous diffusion of membrane components into the alternate surface mem- brane domain. The loss of cellular polarity and the disruption of the cytoskeleton that occur during both the ischemic insult and subsequent reperfusion are fundamental components of the renal tubule insult that accompanies ATP depletion.

\section{RESPONSE OF HEAT SHOCK PROTEINS}

As reviewed in the previous section, restitution of cellular structure and function seems to involve predominantly remodeling and recycling of cellular proteins, at least during the early phase of recovery in sublethally injured cells. Moreover, residual ATP levels (Fig. 2) seem to be conserved for essential processes rather than transport functions $(9,10,58)$. Therefore, the ability to stabilize injured renal epithelium would seem to require a molecular process that has a high affinity for the limited supply of ATP and is capable of intracellular protein handling and trafficking. The heat shock proteins (HSP) are, in fact, a good candidate system that could provide these essential functions for cellular repair and restitution.

HSP are present in nearly all organisms and respond to stresses such as heat, anoxia, and other toxic insults. The HSP occur in a number of different families classified according to their size and apparent functions. Constitutively expressed members of each family provide a variety of functions that assist intracellular protein trafficking. Through unfolding and refolding of peptides, HSP participate in the disassembly of protein aggregates and the translocation of proteins across intracellular membranes (59). Moreover, it has been suggested that these proteins may assist denatured proteins to refold or reassemble into a normal configuration. Within each HSP family, inducible members are expressed in response to cellular injury. The pattern of HSP induction is dependent on cell type and the nature of the insult (59).

The HSP family most likely to be involved in recovery from renal ischemia is the 70-kD group (HSP-70). These proteins are highly inducible in mammalian cells and have distinct cytoprotectant effects. Specific functions attributed to HSP-70 proteins are mediated by a chaperon effect, which allows for proper protein folding by preventing deleterious peptide interactions or aggregations. In addition, the ability of this family of proteins to reactivate denatured proteins has been demonstrated (60). For these constructive activities, the HSP-70 proteins are highly dependent on the hydrolysis of ATP. Moreover, the affinity of these proteins for ATP is so high that binding to ATP has been used to isolate these proteins. This high affinity would be particularly valuable during the recovery from an ischemic event when ATP levels are diminished and would allow the utilization of the residual cellular ATP for important processes directed to stabilization and recovery of tubule cells.

Two groups of investigators have found that renal ischemia, in vivo, rapidly induces the elaboration of HSP-70 proteins $(61,62)$. The message for inducible 
HSP-70 is found within minutes of an ischemic insult and peaks within the first $2-6 \mathrm{~h}$ of reflow after $45 \mathrm{~min}$ of ischemia. HSP-72, the inducible protein, appears shortly after the message and accumulates for the first few days after the injury, persisting for up to $5 \mathrm{~d}$. The inducible protein is found in membrane fractions as well as in soluble cytoplasmic components, suggesting that this HSP may be involved with a variety of other proteins that have been disassembled or denatured as a result of the ischemic insult. The temporal localization of HSP-72 after an ischemic insult has provided some exciting, if indirect, data concerning the possible interaction between HSP and cytoskeletal or integral membrane proteins (Fig. 5). During the first $15 \mathrm{~min}$ of reperfusion, HSP-72 is found almost exclusively in the apical domain of the proximal tubule cells, which is the area of most intense injury. It is at this time that characteristic alterations of the brush border associated with breakdown of the apical cytoskeleton and redistribution of $\mathrm{Na}, \mathrm{K}$ ATPase to the apical membrane have occurred. Between 2 and $6 \mathrm{~h}$ of reperfusion, HSP-72 is found throughout the cytoplasm and corresponds with the diffuse intracellular location of fodrin and $\mathrm{Na}, \mathrm{K}$-ATPase seen at the same recovery period (49). At $24 \mathrm{~h}$ of reperfusion, HSP-72 has migrated away from the apical domain coincident with restitution of cellular polarity. These interesting findings suggest that the induction, elaboration, and localization of HSP-72 may be important contributors to repair of cellular injury after an ischemic insult.

Supporting evidence for HSP-70 proteins having a role in cellular recovery from renal injury has come from studies in cell culture lines and human tissue. Two amino acids, glycine and alanine, have been shown to protect renal tubule cells from ischemic injury through undefined mechanisms $(63,64)$. A opposum kidney tubule cell line has been used to study the effect of glycine and alanine in a heat shock model of injury (65). Neither glycine nor alanine alone induced a HSP-70 response. However, provision of either amino acid during and after the injury resulted in more prominent induction of HSP-70 mRNA and elaboration of protein that correlated with improved cellular viability. These studies suggest that the cellular protective effects of these amino acids may be mediated by enhanced HSP response. A recent study examined in situ expression of HSP-72 in diseased human kidneys (66). Although the pattern of expression varied, HSP-72 was found in proximal tubules and collecting ducts of kidneys that had an ischemic insult or acute tubular necrosis. No HSP-72 was present in normal human kidney. In a heat shock model of collecting duct cell injury, preconditioning with mild heat stress (with HSP-72 accumulation) protected against impairment of cellular aerobic and anaerobic metabolism, which was measured by state III mitochondrial respiration and lactate production (67). This suggests that one mechanism by which HSP might protect or assist recovery of renal epithelial cells is through protection or repair of the cellular processes responsible for ATP production.

Previous studies of ischemic injury have relied on a severe depletion of cellular ATP induced by complete occlusion of the renal artery. Thus, the precise cellular mechanisms that may be responsible for the induction of HSP in response to renal ischemia have not been completely delineated. In a recently developed model of partial depletion of ATP in vivo, activation of heat shock transcription factor (the most proximate step in initiation
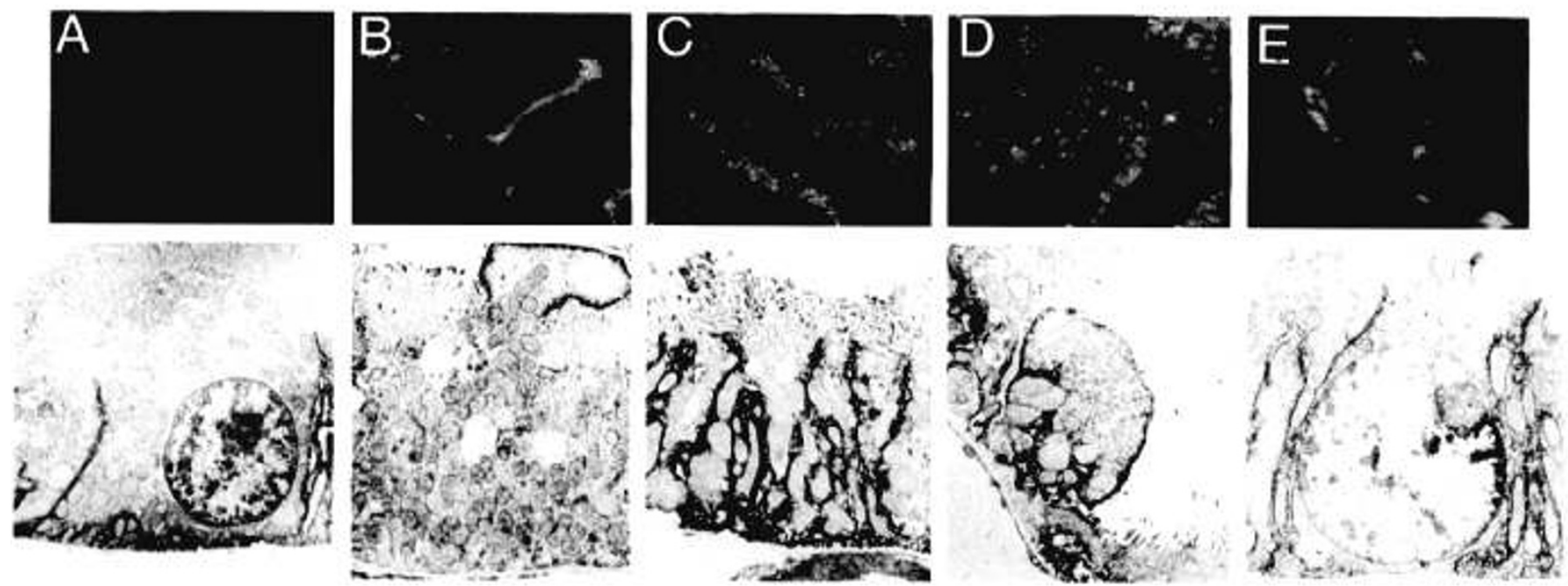

Figure 5. The temporal in situ localization of HSP-72 and Na,K-ATPase after 45 min of ischemia. In the upper panels, HSP-72 was localized using confocal immunofluorescent microscopy of tubule segments (open lumen in center of tubule). In the lower panels, Na,K-ATPase was detected by immunolocalization on electron microscopy (apical border at top, basal domain at bottom). A, Nonischemic controls showed only background fluorescence and basolateral localization of Na,K-ATPase (black areas along bottom and sides). B, At 15 min of reflow, HSP-72 was found predominantly in the apical domain (yellow fluorescence), which is the area of most intense injury, and Na,K-ATPase redistributed to this site (black stain at top). $C$. Two h of reflow; $D, 6$ h of reflow. Between 2 and 6 h of reperfusion, HSP-72 was found throughout cytoplasm (yellow and red fluorescence) and corresponded with diffuse intracellular localization of Na,K-ATPase (black stain at bottom and throughout cell). E, By 24 $\mathrm{h}$ of reflow, HSP-72 had migrated away from the apical domain (yellow and red fluorescence) concomitant with repolarization of Na,K-ATPase (black stain at bottom and sides). 
of an $\mathrm{HSP}$ response) and subsequent induction of HSP-70 mRNA occur only when ATP levels are reduced below $50 \%$ of control values $(60)$. Although cellular ATP seems to be a threshold factor for the initiation of the HSP response, whether the response is directly related to cellular ATP or to a concomitant dissociation of cytoskeletal elements from each other or from integral membrane proteins is unknown. The answer to this question will be of particular importance in understanding the role stress proteins play in the conservation and restoration of cellular integrity. Nevertheless, it is apparent that HSP-72 has a multifaceted relationship with the metabolic state of stressed cells. Induction is associated with ATP depletion; one effect is protection of mechanisms for ATP synthesis, and HSP-72 functions require ATP hydrolysis.

The interesting interrelationships between alterations in cellular metabolic processes, the integrity of cellular structure and function, and those systems that may serve to protect or repair the injured epithelium represent an area of active investigation. Moreover, these interactions represent the type of fundamental biologic processes that may be applicable to a variety of organ systems and types of injury.

Acknowledgments. We are grateful to a large number of individuals who have worked and collaborated with us in our studies of renal cell injury: Michael Kashgarian, Karen M. Gaudio, Gunilla Thulin, Andrea Mann, Hugh Carey, Ivy Boydstun, Tom Ardito, and others. We also acknowledge the administrative support and secretarial assistance of Marie Campbell and Melanie-Dawn Belanger.

\section{REFERENCES}

1. Stein JH, Lifschitz MD, Barnes LD 1978 Current concepts on the pathophysiology of acute renal failure. Am J Physiol 234:F171-F181

2. Donohoe JF, Venkatachalam MA, Bernard DB, Levinsky NG 1978 Tubular leakage and obstruction after renal ischemia: structural-functional correlations. Kidney Int 13:208-222

3. Venkatachalam MA. Patel YJ, Kreisberg JI, Weinberg JM 1988 Energy thresholds that determine membrane integrity and injury in a renal epithelial cell line (LLC.PK1). Relationships to phospholipid degradation and unesterified fatty acid accumulation. J Clin Invest 81:745-758

4. Brezis M, Rosen S, Silva P, Epstein F 1984 Editorial review. Renal ischemia: a new perspective. Kidney Int 26:375-38.3

5. Lieberthal W, Rennke HG, Sandock KM, Valeri CR, Levinsky NG 1988 Ischemia in the isolated erythrocyte-perfused rat kidney. Renal Physiol Biochem 11:60-69

6. Voight MT, Farber E 1968 On the molecular pathology of ischemic renal cell death. Am J Pathol 53:1-26

7. Avison MJ, van Waarde A, Stromski ME, Gaudio KM, Siegel NJ 1989 Metabolic alterations in the kidney during ischemic acute renal failure. Semin Nephrol 9:98-101

8. Stromski ME, Cooper K. Thulin G, Gaudio KM, Siegel NJ, Shulman RG 1986 Chemical and functional correlates of postischemic renal ATP levels. Proc Natl Acad Sci USA 83:6142-6145

9. Gaudio KM. Thulin G, Ardito T, Kashgarian M, Siegel NJ 1991 Redistribution of cellular energy following renal ischemia. Pediatr Nephrol 5:591-596

10. Sakarcan A, Aricheta R, Baum M 1992 Intracellular cystine loading causes proximal tubule respiratory dysfunction: effect of glycine. Pediatr Res 32:710 713

11. van Waarde A, Avison MJ, Thulin G, Gaudio KM, Shulman RG, Siegel NJ 1992 Role of nucleoside uptake in renal postischemic ATP synthesis. Am J Physiol 262:F1092-F1099

12. Ratcliffe PJ, Moonen CTW, Holloway PAH, Ledingham JGG, Radda GK 1986 Acute renal failure in hemorrhagic hypotension: cellular energetics and renal function. Kidney Int 30:355-360
13. Zager RA 1987 Partial aortic ligation: a hypoperfusion model of ischemic acute renal failure and comparison to renal artery occlusion. J Lab Clin Med $110: 396-405$

14. Stromski ME, van Waarde A, Avison MJ. Thulin G, Gaudio KM, Kashgarian M, Shulman RG, Siegel NJ 1988 Metabolic and functional consequences of inhibiting adenosine deaminase during renal ischemia in rats. J Clin Invest 82:1694-1699

15. van Waarde A, Stromski ME, Thulin G, Gaudio KM, Kashgarian M, Shulman RG, Siegel NJ 1989 Protection of the kidney against ischemic injury by inhibition of 5 '-nucleotidase. Am J Physiol 256:F298-F305

16. Gaudio KM, Siegel NJ 1987 New approaches to the treatment of acute renal failure. Pediatr Nephrol 1:339-347

17. Gaudio KM, Ardito TA, Reilly HF, Kashgarian M, Siegel NJ 1983 Accelerated cellular recovery after an ischemic renal injury. Am J Pathol 112:338-346

18. Mandel LJ, Takano T, Soltoff SP, Murdaugh S 1988 Mechanisms whereby exogenous adenine nucleotides improve rabbit renal proximal function during and after anoxia. J Clin Invest 81:1255-1264

19. Weinberg JM, Humes HD 1986 Increases of cell ATP produced by exogenous adenine nucleotides in isolated rabbit kidney tubules. Am J Physiol 250:F720F733

20. Sulter PM, Thulin G, Stromski M, Ardito T, Gaudio KM, Kashgarian M, Siegel NJ 1988 Beneficial effect of thyroxin in the treatment of ischemic acute renal failure. Pediatr Nephrol 2:1-7

21. Boydstun I, Thulin G, Siegel NJ 1992 Mechanism of post-ischemic augmentation of renal ATP by thyroxin. Pediatr Res 31:329A(abstr)

22. Humes HD, Creslinski DA, Johnson LB, Sanchez IO 1992 Triiodothyronine enhances renal tubule cell replication by stimulating EGF receptor gene expression. Am J Physiol 262:F540-F545

23. Weinberg JM 1991 The cell biology of ischemic renal injury. Kidney Int 39:476-50()

24. Epstein FH, Mandel LJ 1992 Forefronts in nephrology: summary of the newer aspects of renal cell injury. Kidney Int 42:52.3-539

25. Rodriguez-Boulan E, Nelson WJ 1989 Morphogenesis of the polarized epithelial cell type. Science 245:718-725

26. Simons K, Wandinger-Ness A 1990 Polarized sorting in epithelia. Cell 62:207210

27. Molitoris BA, Nelson WJ 1990) Alterations in the establishment and maintenance of epithelial cell polarity as a basis for disease processes. J Clin Invest 85:3-9

28. Molitoris BA 1991 New insights into the cell biology of ischemic acute renal failure. J Am Soc Nephrol 1:1263-1270)

29. Molitoris BA 1991 Ischemia-induced loss of epithelial polarity: potential role of the actin cytoskeleton. Am J Physiol 26():F769_F778

30. Vega-Salas EE, Salas PJI, Rodriguez-Boulan E 1988 Exocytosis of the vacuolar apical compartment (VAC). J Cell Biol 107:1717-1728

31. Nelson WJ, Veshnock PJ 1986 Dynamics of membrane-skeleton (fodrin) organization during development of polarity in MDCK epithelial cells. J Cell Biol 103:1751-1765

32. Caplan MJ, Anderson HC, Palade GE, Jamieson JD 1986 Intracellular sorting and polarized cell surface delivery of $(\mathrm{Na}, \mathrm{K}) \mathrm{ATPase}$, an endogenous component of MDCK cell basolateral plasma membranes. Cell 46:623-631

33. Hunziker W, Harter C, Matter K, Mellman I 1991 Basolateral sorting in MDCK cells requires a distinct cytoplasmic domain determinant. Cell 66:623631

34. Hammerton RW, Krzeminski KA, Mays RW, Ryan TA, Wollner DA, Nelson WJ 1991 Mechanism for regulating cell surface distribution of Na,K-ATPase in polarized epithelial cells. Science 254:847-850

35. McNeill H, Ozawa M, Kemler R, Nelson WJ 199) Novel function of the cell adhesion molecule uvomorulin as an inducer of cell surface polarity. Cell 62:309-316

36. Bennett V, Lambert $S 1991$ The spectrin skeleton: from red cells to brain. J Clin Invest 87:1483-1489

37. Molitoris BA, Dahl R, Geerdes A 1992 Cytoskeletal disruption and apical redistribution of proximal tubule Na,K-ATPase during ischemia. Am J Phys. iol 263:F488-F495

38. Kashgarian M. Biemesderfer D, Caplan M, Forbush III B 1985 Monoclonal antibody to Na,K-ATPase: identification, characterization, and use in immunocytochemical localization along nephron segments. Kidney Int 28:899_913

39. Morrow JS, Cianci C. Ardito T, Mann A, Kashgarian M 1989 Ankyrin links fodrin to Na,K-ATPase in MDCK and renal tubule cells. J Cell Biol 108:455465

40. Koob R, Zimmerman M, Schoner W, Drenkahn D 1987 Colocalization and coprecipitation of ankyrin and Na,K-ATPase in kidney epithelial cells. Eur $\mathrm{J}$ Cell Biol 45:2301-237

41. Nelson WJ, Veshnock PJ 1987 Modulation of fodrin (membrane skeleton) stability by cell-cell contact in MDCK celis. J Cell Biol 1(1)4:1527-1537

42. Nelson WJ, Veshnock PJ 1987 Ankyrin binding to Na,K-ATPase and implications for the organization of membrane domains in polarized cells. Nature (Lond) 328:5.33-5.36

43. Nelson WJ, Hammerton RW 1989 A membrane-cytoskeletal complex con taining $\mathrm{Na}, \mathrm{K}-\Lambda \mathrm{TPase}$, ankyrin and fodrin in MDCK cells: implications for the biogenesis of epithelial cell polarity. J Cell Biol 108:893-902

44. Molitoris BA, Hoilien CA, Dahl RH, Ahnen DJ, Wilson PD, Kim J 1988 Characterization of ischemia-induced loss of epithelial polarity. J Membr Biol $106: 233-242$ 
45. Molitoris BA, Chan LK, Shapiro JL, Conger JD, Falk SA 1989 I oss of epithelial polarity: a novel hypothesis for reduced proximal tubule $\mathrm{Na}^{+}$ transport following ischemic injury. J Membr Biol 107:117-127

46. Spiegel DM, Wilson PD, Molitoris BA 1989 Epithelial polarity following ischemia: a requirement for normal cell function. Am J Physiol 256:F430 F436

47. Johnston PA, Rennke HG, Levinsky NG 1984 Recovery of proximal tubular function from ischemia. Am J Physiol 246:F159-Fl66

48. Molitoris BA. Wilson PD. Schrier RW, Simon FR 198.5 lschemia induces partial loss of surface membrane polarity and accumulation of putative calcium ionophores. J Clin Invest 76:2097-2105

49. Kashgarian M, Van Why SK, Hildebrandt F, Mann AS, Gaudio KM, Siegel NJ 1991 Regulation of expression and polar distribution of Na,K-ATPase in renal epithelium during recovery from ischemic injury. In: Kaplan JH, De Weer P (eds) The Sodium Pump: Recent Developments. Rockefeller University Press, New York, pp 573-577

50. Van Why SK, Mann AS, Ardito T, Siegel NJ, Kashgarian M 1994 Expression and molecular regulation of $\mathrm{Na}, \mathrm{K}-\mathrm{ATP}$ ase after renal ischemia. Am J Physiol (in press)

5t. Lee KS, Frank S, Vanderklish P, Arai A, Lynch G 1991 Inhibition of proteolysis protects hippocampal neurons from ischemia. Proc Natl Acad Sc USA 88:7233-7237

52. Doctor RB. Bennett V, Mandel I J 1993 Degradation of spectrin and ankyrin in ischemic rat kidney. Am J Physiol 264:C10(0)3-Cl(013

53. Carey H, Ardito T, Mann A Siegel NJ, Kashgarian M 1993 Fodrin processing is temporally associated with loss and recovery of epithelial cell polarity following ischemic renal injury. J Am Soc Nephr 4:73,3

54. Kellerman PS, Clark RAF, Hoilien CA, Linas SL, Molitoris BA 1490) Role of microfilaments in the maintenance of proximal tubule structural and functional integrity. Am J Physiol 259:F279-F285

55. Molitoris BA. Geerdes A, Mclntosh JR 1991 Dissociation and redistribution of $\mathrm{Na}, \mathrm{K}-\mathrm{ATP}$ ase from its surface membrane actin cytoskeletal complex during cellular ATP depletion. J Clin Invest 88:462-469
56. Molitoris BA, Falk SA, Dahl RH 1489 Ischemia-induced loss of epithelial polarity: role of the tight junction. J Clin Invest $84: 1334-1339$

57. Imhof BA. Vollmers HP, Goodman SL. Birchmeier W 198.3 Cell-cell inter action and polarity of epithelial cells: specific perturbation using a monoclona antibody. Cell 35:667-675

58. Gaudio KM, Thulin G, Ardito T, Kashgarian M, Siegel NJ 1989 Metabolic alterations in proximal tubule suspensions obtained from ischemic kidneys. Am J Physiol 257:F383-F384

59. Nover L (ed) 1991 Heat Shock Response. CRC Press. Boca Raton, FI.

60. Skowyra D, Georgopoulos (, Zylicz M 1990) The $t$. coli DNA K gene product, the HSP 70) homolog, can reactivate heat-inactivated RNA polymerase in an ATP hydrolysis-dependent manner. Cell 62:939_444

61. Emami A. Schwartz JH, Borkan SC 1991 Transient ischemia or heat stress induces a cytoprotectant protein in rat kidney. Am J Physiol 266):F479_F485

62. Van Why SK. Hildehrandt F. Ardito T, Mann AS, Sicgel NJ, Kashgarian M 199.3 Induction and intracellular localization of HSP-72 after renal ischemia. Am J Physiol 263:F769-F775

63. Weinberg JM. Davis JA. Abarzua M. Rajan T 1987 Cytoprotective effects of glycine and glutathione against hypoxic injury to renal tubules. J Clin Invest $8(1): 1446-1454$

64. Garza-Quintero R, Ortega-Lopez J, Stein JH, Venkatachalam MA 1990 Alanine protects rabbit proximal tubules against anoxic injury in vitro. $\mathrm{Am} \mathrm{J}$ Physiol 248:F1(175-F1083

65. Nissam I, Hardy M. Pleasure J, Nissam I, States B 1992 A mechanism of glycine and alanine cytoprotective action: stimulation of stress-induced HSP-70 mRNA. Kidney Int 42:775-782

66. Dodd SM, Martin JE. Swash M. Mather K 194,3 Expression of heat shock protein epitopes in renal disease. Clin Nephrol 39:239-244

67. Borkan SC. Emami $\Lambda$. Schwartz JH 1993 Heat stress protein-associated cytoprotection of inner medullary collecting duct cells from rat kidney. Am J Physiol 199.3 265:F333-F.341

68. Van Why S, Mann A. Thulin G, Zhu X. Kashgarian M, Siegel NJ 1993 Cellular ATP as a threshold for heat shock response in renal cortex. J Am Soc Nephrol 4:746(abstr). 